\title{
MAPEAMENTO DO USO VARIÁVEL DO MODO SUBJUNTIVO NO PORTUGUÊS DO BRASIL ${ }^{1}$ MAPPING THE VARIABLE USE OF THE PRESENT OF THE SUBJUNCTIVE MOOD IN BRAZILIAN PORTUGUESE
}

\author{
Tatiana Schwochow Pimpão \\ Docente do Instituto de Letras e Artes da Universidade Federal do Rio Grande \\ tatiana.pimpao@hotmail.com
}

RESUMO: O objetivo deste artigo é realizar um mapeamento do uso variável do modo subjuntivo no português do Brasil, a partir da comparação dos resultados gerais obtidos em 18 pesquisas com amostras de quatro regiões brasileiras: Sul, Sudeste, Nordeste e Centro-Oeste. A importância dos percentuais reside na indicação da frequência do subjuntivo em cada amostra investigada. Nesse sentido, qualquer comparação mais rigorosa inferida a partir dos resultados deve considerar as particularidades de cada estudo. O mapeamento inicial permite um panorama muito interessante sobre o uso variável do modo subjuntivo e coloca em destaque algumas variáveis, como modalidade e tipo de oração. A despeito de especificidades que caracterizam as amostras e o controle das variáveis, o uso variável do modo subjuntivo parece seguir um certo padrão, pelo menos no que se refere às duas variáveis mencionadas. Os trabalhos constituem referência, portanto, para a comparação de resultados relativos às mesmas variáveis na tentativa de uma maior compreensão do funcionamento do uso variável do presente dosubjuntivo.

PALAVRAS-CHAVE: Modo subjuntivo. Variação. Regiões brasileiras.

ABSTRACT: The objective of this researchis to map the variable use of subjunctive mood in Brazilian Portuguese from the comparison of the general results obtained in 18 samples from four Brazilian regions: South, Southeast, Northeast and Midwest. The importance lies in percentage of the subjunctive in each sample investigated. In this sense, any rigorous comparison inferred from the results should consider the particularities of each study. The initial mapping allows a very interesting overview on the variable use of the subjunctive mood and it highlights on some variables such as modality and type of clause. In spite of specificities that characterize the samples and the variables controlled, the variable use of the subjunctive mood seems to follow a certain pattern, at least with regard to the two variables mentioned. The studies are therefore reference for comparison results for the same variables in an attempt to a better understanding operation of the variable use of the present subjunctive.

KEYWORDS: Subjunctive mood. Variation. Brazilian regions.

\section{INTRODUÇÃO}

Tem crescido, no Brasil, o interesse pela pesquisa acerca da variação entre o modo subjuntivo e o modo indicativo, desde a década de 1970 e se intensificando a partir do ano 2000 (BOTELHO PEREIRA, 1974; WHERRITT, 1977; COSTA, 1990; ROCHA, 1997; PIMPÃO, 1999; ALVES NETA, 2000; GONÇALVES, 2003; GUIRALDELLI, 2004; SANTOS, 2005; MEIRA, 2006; CARVALHO, 2007; FAGUNDES, 2007;

\footnotetext{
${ }^{1}$ Este artigo parte de um recorte da tese de doutorado defendida junto ao Programa de Pós-Graduação em Linguística da Universidade Federal de Santa Catarina intitulada "Uso variável do presente no modo subjuntivo: uma análise de amostras de fala e escrita das cidades de Florianópolis e Lages nos séculos XIX e XX”.
} 
OLIVEIRA, 2007; VIEIRA, 2007; ALVES, 2009; ALMEIDA, 2010; BARBOSA, 2011; PIMPÃO, 2012). Dentre esses trabalhos, o de Alves (2009), o de Almeida (2010) e o de Pimpão (2012) conjugam a análise de amostras sincrônica e diacrônica.

As referidas pesquisas descrevem procedimentos metodológicos diferenciados: por exemplo, algumas tratam da variação no presente do modo subjuntivo; outras, da variação no presente e no passado do modo subjuntivo; e outras ainda investigam os três tempos desse modo verbal. A distinção entre os estudos também se concentra no contexto de análise: ora as orações substantivas; ora as substantivas e as adjetivas; ora, todas orações subordinadas (adjetivas, adverbiais e substantivas) e ainda os casos com o talvez, para ilustrar a diversidade no foco de investigação.

A despeito dessas particularidades, o objetivo deste artigo é realizar um mapeamento do uso variável do subjuntivo no português do Brasil, a partir da comparação dos resultados gerais obtidos nessas pesquisas com amostras de diferentes regiões brasileiras. Este artigo está assim organizado: na sequência da introdução, uma contextualização do modo subjuntivo a partir da revisão teórica em algumas gramáticas normativas; a seguir, uma breve descrição dos contextos de emprego desse modo verbal; e (iii) o mapeamento do modo subjuntivo a partir de resultados de pesquisas realizadas com dados do português do Brasil. Seguem-se as considerações finais.

\section{CONTEXTUALIZAÇÃO DO MODO SUBJUNTIVO}

Há uma certa uniformidade entre as gramáticas normativas modernas que seguem a linha das gramáticas tradicionais (daqui em diante denominadas indistintamente como gramáticas normativas ou gramáticas tradicionais) no que se refere à definição do modo subjuntivo e/ou descrição do emprego desse modo verbal, a partir de atitudes dos falantes que se contrapõem às atribuídas ao modo indicativo. Se ao indicativo são associadas atitudes de certeza, de realidade, ao subjuntivo são atribuídas atitudes opostas, conforme se observa, a título de ilustração, nos excertos a seguir:

SUBJUNTIVO (CONJUNTIVO) - em referência a fatos incertos: talvez cante, se cantasse $^{2}$ (BECHARA, 2006, p. 221, grifos do autor). Emprega-se o modo subjuntivo para exprimir um fato possível, incerto, hipotético, irreal ou dependente de outro (CEGALLA, 2007, p. 588). Ao empregarmos o MODO SUBJUNTIVO, é completamente diversa a nossa atitude. Encaramos, então, a existência ou não existência do fato como umacoisa incerta, duvidosa, eventual, ou, mesmo, irreal ${ }^{3}$ (CUNHA; CINTRA, 2007, p. 479, grifos dos autores).

Indica este modo que o verbo não tem sentido caso não venha subordinado a outro verbo, do qual dependerá para ser perfeitamente compreendido. [...] O modo subjuntivo indica dependência também quando o fato é duvidoso ou indeterminado, sendo por isso chamado 'modo da possibilidade' (MENDES DE ALMEIDA, 2005, p. 226, grifo do autor).

Considerando a caracterização do modo subjuntivo apresentada por esses gramáticos, infere-se que o vir a ser constitui o traço recorrente associado a esse modo

\footnotetext{
2 À exceção de Bechara (2006), os demais gramáticos mencionados neste artigo consideram a existência de três modos verbais: indicativo, subjuntivo e imperativo. Para Cegalla (2007, p. 589, gripo do autor), o optativo constitui um dos empregos do subjuntivo: "Que elas envolvam no seu aroma a vossa memória." Além do modo subjuntivo, Bechara (2006, p. 222, grifo do autor) inclui o modo optativo: "em relação à ação como desejada pelo agente: E viva eu cá na terra sempre triste."

${ }^{3}$ Cunha (1992) apresenta a mesma definição para o modo subjuntivo.
} 
verbal uma vez que o subjuntivo é o modo do desejo, da súplica, incerteza, dúvida, possibilidade, hipótese, irrealidade, eventualidade, vontade, ordem, proibição, indeterminação. Ressalta-se, ainda, a referência de Cunha e Cintra (2007) e Mendes de Almeida (2005) à dependência sintático-semântica: a oração com o subjuntivo depende de uma outra oração, encerrando esta um fato possível, desejado, incerto etc. $O$ subjuntivo, portanto, é tratado no âmbito da morfossintaxe: a morfologia desse modo verbal carrega um significado que corresponde à atitude de incerteza, por exemplo, ainda que seu emprego esteja subordinado a determinados tipos de orações.

Posto dessa forma, o subjuntivo é considerado o modo da subordinação ainda que nem todos os casos de subordinação impliquem o uso desse modo verbal. Por exemplo, o presente do indicativo é praticamente de uso categórico sob o escopo do verbo achar e de uso categórico sob o escopo do verbo parecer, conforme ilustram os dados a seguir (PIMPÃO, 2012, p. 32-33).

(1) É só eu e as crianças. Então eu faço de tudo pra mim não parar pra pensar, porque eu sei que se eu parar pra pensar, ACHO QUE eu VOU enlouquecer. (FLP 03, L407)

(2) porque você já se conhece muito mais do que você se conhecia, então aí aparece o filho, quer dizer, o filho, PARECE QUE você RECOMEÇA tudo de novo, está recomeçando tudo de novo, tá? Mas daí PARECE QUE a coisa VAI, e aí começa a vir outras realidades que você não conhecia, como educar a criança, como tratar a criança ma questão da saúde, como dar os encaminhamentos necessários aí, né? (LGS 03, L730-732)

De acordo com os dados (1) e (2), observamos que há casos de subordinação em que o uso do subjuntivo não se mostra predominante. No entanto, para Said Ali (1971), os verbos achar e parecer podem ocorrer com o verbo da oração subordinada no modo subjuntivo ou no modo indicativo, caso o fato seja considerado real.

Na sequência, veremos os contextos de emprego do modo subjuntivo descritos nas gramáticas de Cunha (1992), Mendes de Almeida (2005), Bechara (2006), Cegalla (2007) e Cunha e Cintra (2007). ${ }^{5}$

\section{CONTEXTOS DE EMPREGO DO MODO SUBJUNTIVO}

As gramáticas tradicionais enumeram as condições de emprego do modo subjuntivo em orações independentes e em orações subordinadas. Dentre as orações independentes, o subjuntivo pode expressar dúvida, precedido, geralmente, pelo talvez ${ }^{6}$. Nas orações dependentes, emprega-se o subjuntivo em certas orações substantivas, adjetivas e adverbiais.

\footnotetext{
${ }^{4} \mathrm{O}$ código entre parênteses oferece informações acerca da entrevista: cidade (Florianópolis (FLP) e Lages (LGS)), número e linha da entrevista. As entrevistas estão disponíveis no Banco de Dados do Projeto VARSUL. Informações sobre o Projeto VARSUL podem ser acessadas no site: http://www.varsul.org.br. ${ }^{5}$ Como este artigo vincula-se à tese de doutorado de Pimpão (2012) acerca do uso variável do presente do modo subjuntivo, os contextos de emprego desse modo verbal, descritos na seção 3 , dizem respeito, especialmente, ao tempo presente.

6 Além das orações independentes que expressam dúvida, geralmente com o advérbio talvez, as gramáticas consideram, ainda, os seguintes usos claramente modalizados: expressão de um desejo, de uma hipótese, de uma ordem, de uma exclamação denotadora de indignação.
} 


\subsection{Orações com talvez}

Dentre o emprego do subjuntivo em orações independentes estão as orações dubitativas com o talvez, não se registrando, necessariamente, impedimento ao emprego do indicativo:

Magistrado ou guerreiro de justo ou generoso se gaba: - e as turbas talvez o aplaudem e celebram seu nome. Parece que o indicativo deixa antever melhor a certeza de que o que se duvida se pode bem realizar. ${ }^{7}$ (BECHARA, 2006, p. 281, grifos do autor).

É comum as gramáticas normativas associarem o emprego do modo subjuntivo a orações independentes com o talvez. Cegalla (2007, p. 588-589), entretanto, prevê o emprego do subjuntivo em orações coordenadas ("Talvez ela compreendesse e lhe perdoasse.") e em orações principais ("Talvez não mereçamos imaginar que haverá outros verões.").

\subsection{Orações Substantivas}

Emprega-se o subjuntivo depois ${ }^{8}$ :

1) de expressões "(verbos, nomes ou locuções equivalentes) que denotam ordem, vontade, consentimento, aprovação, proibição, receio, admiração, surpresa, contentamento": proibir, esperar (BECHARA, 2006, p. 281). Cunha e Cunha (1992, p. 444) e Cintra (2007, p. 482) referem-se à "vontade, nos matizes que vão do comando ao desejo": querer, admitir, querer e gostar. Mendes de Almeida (2005) lista alguns verbos volitivos (de desejo e de vontade): aconselhar, admitir, consentir, deixar, desejar, determinar, estabelecer, exigir, impedir, obrigar, ordenar, pedir, preferir, querer, recomendar, rogar, suplicar etc.

2) de expressões "(verbos ou locuções formadas por ser, estar, ficar + substantivo ou adjetivo) que denotam desejo, probabilidade, vulgaridade, justiça, necessidade, utilidade": cumprir, convir, ser bom que (BECHARA, 2006, p. 281). Cunha e Cunha (1992, p. 445) e Cintra (2007, p. 482) mencionam "um sentimento, ou uma apreciação que se emite com referência ao próprio fato em causa": ser melhor que. Mendes de Almeida (2005) apresenta outros verbos: esperar, gostar, importar, temer, tomara que etc., e outras com ser + importante, impossível, incrível, necessário, possível, preciso etc.

Said Ali (1971, p. 330) faz um comentário interessante: “orações que denotam fatos em contradição com a expectativa, usam-se com o verbo no conjuntivo quando servem de complemento" a, por exemplo, ser incrivel que. Ainda segundo esse autor, ser necessário, ser justo, ser bom, importar, cumprir e bastar requerem o subjuntivo. Ressalva apenas para o verbo bastar, que, referindo-se a um fato real, fica acompanhado do indicativo.

\footnotetext{
${ }^{7}$ Cunha (1992), Mendes de Almeida (2005), Cegalla (2007) e Cunha e Cintra (2007) não mencionam a possibilidade de uso do indicativo sob o escopo do advérbio talvez. Para Mendes de Almeida (2005), por exemplo, o advérbio exige o emprego do subjuntivo quando anteposto a ele.

${ }^{8}$ Esse emprego do subjuntivo é apresentado por Cunha (1992), Mendes de Almeida (2005), Bechara (2006) e Cunha e Cintra (2007).

${ }^{9}$ Para Said Ali (1971), os verbos temer e esperar podem vir também acompanhados do verbo no indicativo. Entretanto, os exemplos apresentados estão somente no futuro no presente. Ainda assim, observamos a possibilidade de uso do modo indicativo.
} 
3) dos verbos "duvidar, suspeitar, desconfiar e nomes cognatos (dúvida, duvidoso, suspeita, desconfiança, etc.) quando empregados, isto é, quando se trata de dúvida, suspeita ou desconfiança reais"10 (BECHARA, 2006, p. 281). A dúvida ${ }^{11}$ "quanto à realidade do fato enunciado" também é mencionada por Cunha e por Cunha (1992, p. 445) e Cintra (2007, p. 482): poder ser que, recear ${ }^{12}$, não acreditar. Eis alguns exemplos citados por Cegalla (2007, p. 589): ser possível que ${ }^{13}$, acreditar, supor;

Para Said Ali (1971, p. 327), os verbos crer, cuidar, pensar, supor, imaginar, entender, presumir, achar e parecer, na oração principal, apresentam a seguinte peculiaridade: "por meio de oração substantiva que exprima um fato considerado como real, o verbo desta segunda oração se diz em geral no indicativo, algumas vêzes porém no conjuntivo"14. Mendes de Almeida (2005, p. 567) destaca que, com determinados verbos, havendo suposição ou incerteza, o subjuntivo deve ser empregado; "ficará no indicativo se a ideia propender para a realização": acreditar, supor, pensar.

Também para Said Ali (1971, p. 328), o indicativo constitui a forma adequada para "exprimir um fato real ou atual em relação ao tempo presente ou passado dos verbos crer, cuidar, pensar, etc." Se algum tipo de realização futura estiver envolvida, o subjuntivo é, portanto, requerido. Outros verbos mencionados por Said Ali (1971, p. 330-331) requerem o subjuntivo: permitir, admitir, impedir, proibir, recomendar, aconselhar, ordenar, fazer, querer, pedir, rogar, suplicar, implorar, desejar, para "atos a serem executados ulteriormente" ou "cuja realização se aspira".

\subsection{Orações Adjetivas}

O subjuntivo ocorre nas orações adjetivas que expressam um fim, uma consequência, uma conjectura e depois de "um predicado negativo, ou de uma interrogação de sentido negativo quando enunciam uma qualidade que determine e restrinja a ideia expressa por esse predicado ou interrogação" (BECHARA, 2006, p. 281-282). Cunha e Cunha (1992) e Cintra (2007) igualmente referem-se a um fim/uma consequência, a um fato improvável, a uma conjectura/hipótese. Mendes de Almeida (2005), ainda que não subdivida os empregos do subjuntivo nas orações adjetivas, está em consonância com os demais gramáticos.

Para Said Ali (1971, p. 326, grifos do autor), a negação de asserções com sujeito indefinido faz com o que o verbo da segunda oração vá para o subjuntivo: "Em um bello dia não ha vento que encrespe as aguas, que perturbe as aves, e que desfolhe as flores." Ainda de acordo com o autor, a oração existencial com pronome quem, independente da presença da negação, está acompanhado do subjuntivo na segunda oração (cf. MENDES DE ALMEIDA, 2005).

\footnotetext{
10 "Se o falante tem a suspeita como coisa certa, ou nela acredita, o normal é aparecer o indicativo." (BECHARA, 2006, p. 281).

${ }^{11}$ Verbos como crer e pensar, ainda que imprimam um valor de incerteza ao enunciado, são usados, segundo Cunha (1992), com indicativo desde que na forma afirmativa.

12 Mendes de Almeida (2005) considera o verbo recear como de sentimento e não como de dúvida.

13 Para Said Ali (1971), no português moderno, a expressão impessoal ser possível que pode vir acompanhada de um verbo no subjuntivo ou no indicativo.

${ }^{14}$ Importante mencionar que os exemplos apresentados por Said Ali (1971) para o conjuntivo estão apenas no passado. Algumas pesquisas com dados do português do Brasil apresentam evidências de um menor índice de variação no imperfeito do subjuntivo se comparado ao presente desse mesmo modo.
} 


\subsection{Orações Adverbiais ${ }^{15}$}

Nas orações adverbiais, o presente do subjuntivo ocorre depois de determinados tipos de orações (cf. BECHARA, 2006; CUNHA, 1992). Para Cunha e Cintra (2007, p. 484), nas orações adverbiais, o subjuntivo, “em geral, não tem valor próprio. É um mero instrumento sintático de emprego regulado por certas conjunções". A seguir, as orações mencionadas pelos gramáticos:

1) causais (não porque, não que);

2) concessivas (ainda que, embora, conquanto, posto que, se bem que, mesmo que, por muito que, por pouco que e semelhantes $)^{16}$;

3) nas condicionais (contanto que, sem que, a não ser que, suposto que, caso, dado que), para exprimir uma hipótese ${ }^{17}$;

4) nas consecutivas, quando exprimem uma concepção, não podendo exprimir, portanto, um fato real;

5) nas finais (para que, a fim de que);

6) nas temporais (antes que, até que, logo que), quando exprimem uma concepção e não um fato real.

Segundo Said Ali (1971, p. 333), o modo subjuntivo era usado com as orações concessivas "de cem anos a esta parte [...] A linguagem dos séculos precedentes socorria-se ora do indicativo, ora do conjuntivo nas orações de ainda que", e o modo verbal indicava se o fato era real ou imaginado. Ao tratar das orações concessivas, Azeredo (2008) destaca que as conjunções apesar de e embora apresentam uma informação considerada real; e o conector se bem que, empregado para introduzir ressalva, ocorre tanto com verbo no indicativo quanto no subjuntivo.

\subsection{Orações Parentéticas}

Mendes de Almeida (2005, p. 567) apresenta um emprego do subjuntivo "nas intercaladas, começadas por que, tomado substantivamente, quando limitam uma possibilidade: Que me LEMBRE, ele não disse isso (pelo que me lembro)". Dentre os casos particulares mencionados por Bechara (2006, p. 283), destacamos o seguinte: "Também têm o verbo no subjuntivo as orações introduzidas por que, quando restringem a generalidade de um asserto: Não há, que eu saiba, expressão mais suave."

Alguns aspectos adicionais merecem destaque a título de observação. Após listar os contextos de uso do subjuntivo, Bechara (2006) observa que os casos por ele destacados não contemplam a complexidade dos modos verbais em português, podendo o falante buscar outras formas expressivas. Para o autor (2006, p. 283), "são questões que fogem ao âmbito da Gramática e constituem preocupação da estilística".

\footnotetext{
${ }^{15}$ Listamos tão somente as orações adverbiais e respectivas conjunções que possam ocorrer com o presente do subjuntivo.

${ }^{16}$ Após listar as conjunções/locuções conjuntivas concessivas com as quais o subjuntivo ocorre, Bechara (2006, p. 282) menciona que não há “completo rigor a respeito.” Mendes de Almeida (2005, p. 566) afirma o seguinte: "Era muito frequente entre os clássicos o indicativo, e ainda hoje é ele empregado quando se quer insistir no fato real: Ainda que a noite era de junho, não fazia apetecível a temperatura."

${ }^{17}$ Para as condicionais, ou condições, conforme sua terminologia, Bechara (2006, p. 282) ressalva que "se se tratar de coisa real ou tida como tal, geralmente aparece o indicativo".
} 


\section{DESCRIÇÃO DO USO VARIÁVEL DO MODO SUBJUNTIVO}

O objetivo desta seção é apresentar uma amostra das pesquisas acerca do uso variável do modo subjuntivo a partir de dados do português do Brasil. Os trabalhos variacionistas $^{18}$ são reunidos por região ${ }^{19}$, conforme distribuídos a seguir.

(1) Região Sul: Costa (1990), com amostras de fala e de entrevistas e debates radiofônicos da zona rural de Ijuí/RS; Pimpão (1999), com dados de fala de informantes do VARSUL/Florianópolis/SC; Fagundes (2007), com córpus ${ }^{20}$ falado das quatro cidades do Banco VARSUL/Paraná (Curitiba, Irati, Londrina e Pato Branco); Pimpão (2012), com dados de fala de informantes do VARSUL/Florianópolis/SC e Lages/SC e dados de escrita provenientes de cartas ao leitor de jornais dessas duas cidades.

(2) Região Sudeste: Botelho Pereira (1974), com testes aplicados no Rio de Janeiro; Wherritt (1977), com dados de fala de São Paulo; Rocha (1997), com dados de fala de Brasília e do Rio de Janeiro/RJ ${ }^{21}$; Alves Neta (2000), com dados de fala e de escrita de Januária/MG; Gonçalves (2003), com dados de fala de professores, programas de TV e situações do cotidiano; Guiraldelli (2004), a partir da análise de um córpus escrito composto por discursos políticos presidenciais e discursos de divulgação científica; Santos (2005), com dados de fala do Rio de Janeiro/RJ e do noroeste de São Paulo/SP; Almeida (2010), com dados de escrita do século XIII ao século XX e amostra de dados de fala culta (NURC-RJ/SSA) e não-culta (PEUL); Barbosa (2011), com dados de fala de informantes do PORTVIX/Vitória/ES.

(3) Região Nordeste: Meira (2006), com amostras de dados de fala oriundos de comunidades afro-brasileiras de zonas rurais da Bahia/BA; Carvalho (2007), com dados de fala da região do Cariri/CE; Vieira (2007), com amostras de dados de fala de Natal/RN; Oliveira (2007), com amostras de fala do VALPB/João Pessoa/PB; Alves (2009), com amostra escrita do século XVI e amostras de fala de Muriaé/MG e de Feira de Santana/BA ${ }^{22}$.

$\mathrm{Na}$ sequência, são brevemente apresentados os trabalhos variacionistas mencionados, reunidos por região.

\subsection{Região Sul}

\section{Costa (1990)}

A pesquisa de Costa (1990) analisa, dentre outros fenômenos relacionados com a flexão verbal, a variação entre os três tempos do modo subjuntivo e do modo indicativo na fala de informantes camponeses descendentes de imigrantes italianos, na vila rural de Santo Antônio, na cidade de Ijuí, no noroeste do Rio Grande do Sul. São cinco os contextos de análise: orações substantivas, relativas, adverbiais, exortativas e com talvez.

\footnotetext{
18 Os estudos com o enfoque variacionista não excluem a possibilidade de incorporação de outra perspectiva teórica, em interface.

19 Buscas realizadas na internet não identificaram pesquisas acerca da variação no modo subjuntivo realizadas com amostras de dados provenientes da Região Norte.

20 A palavra córpus está acentuada, seguindo a regra de acentuação do português para palavras paroxítonas temrinadas em $\mathrm{u}(\mathrm{s})$.

${ }^{21}$ Considerando que grande parte dos dados de Rocha (1997) provém de amostras do Rio de Janeiro, decidimos referir o trabalho na Região Sudeste, ainda que a autora também contemple a análise de dados de Brasília (Região Centro-Oeste).

${ }^{22}$ Alves (2009) investiga dados de duas regiões do Brasil: Sudeste (Muriaé/MG) e Nordeste (Feira de Santana/BA). Considerando o número expressivo de pesquisas realizadas na Região Sudeste, decidimos referir o estudo de Alves (2009) na Região Nordeste.
} 


\section{Pimpão (1999)}

A segunda pesquisa reportada com dados da Região Sul é de Pimpão (1999), que investiga a variação entre as formas verbais do presente do modo subjuntivo e do presente do modo indicativo em entrevistas de Florianópolis/SC (Projeto VARSUL) em cinco contextos linguísticos de variação: cláusulas substantivas, cláusulas relativas ${ }^{23}$, cláusulas adverbiais, com advérbio talvez e pressuposição ${ }^{24}$. Como resultado da primeira rodada estatística geral, que inclui todos os cinco contextos, o pacote estatístico VARBRUL selecionou as seguintes variáveis em sua ordem de significância: tempomodalidade, pessoa, paralelismo sintático e contexto de subjuntivo. Mesmo com alguns amálgamas, em uma segunda rodada o programa selecionou as mesmas variáveis, mantendo, inclusive, a ordem de significância.

\section{Fagundes (2007)}

A partir da análise de dados do Projeto VARSUL do Paraná (cidades de Curitiba, Irati, Londrina e Pato Branco), Fagundes (2007) investiga os três tempos verbais do modo subjuntivo em variação com formas verbais do modo indicativo. Os contextos de análise são os seguintes: orações substantivas, relativas, adverbiais, isoladas e principais. Dentre as variáveis controladas, três obtêm significância estatística: cidade, tipo de oração e modalidade.

\section{Pimpão (2012)}

Pimpão (2012) retoma a investigação da variação entre o presente do modo subjuntivo e o presente do modo indicativo em dados de fala e de escrita. Os dados de fala são provenientes de entrevistas com informantes das cidades de Florianópolis/SC e Lages/SC (Projeto VARSUL); os dados de escrita, da seção cartas ao leitor de jornais de ambas as cidades, da segunda metade do século XIX até o final do século XX. Cinco contextos de ocorrência da variação são analisados: orações substantivas, adjetivas, adverbiais, parentéticas e com o talvez.

Um ponto em comum entre as pesquisas está em algumas variáveis controladas: as que tratam de modalidade e de tipo de oração. Nas três pesquisas, essas variáveis são consideradas e, em Pimpão (1999) e Fagundes (2007), obtiveram relevância estatística. Nesse sentido, ainda que as amostras não possam ser comparáveis sem restrições (número de dados, constituição do banco, por exemplo), a importância dessas variáveis não pode passar despercebida.

\subsection{Região Sudeste}

\section{Botelho Pereira $(1974)^{25}$}

Botelho Pereira (1974) investiga a oposição modal entre os modos indicativo e subjuntivo no presente e no pretérito, tendo como contexto de análise as orações substantivas introduzidas por que. Para a análise dos casos, Botelho Pereira (1974, p.

\footnotetext{
${ }^{23}$ Como respeitamos a terminologia adotada pelo pesquisador, o leitor poderá encontrar denominações diferenciadas para os mesmos tipos de contextos em análise, como, por exemplo, a opção do pesquisador por oração adjetiva ou oração relativa.

${ }^{24}$ Em Pimpão (1999), esse contexto é denominado pressuposição. Em Pimpão (2012), o referido contexto passa a ser denominado orações parentéticas.

${ }^{25}$ Na pesquisa de Botelho Pereira (1974), não há referência à origem dos informantes selecionados para a aplicação de testes. Considerando que a autora realizou sua pesquisa no Rio de Janeiro, acreditamos que os informantes sejam fluminenses, razão pela qual inserimos seu estudo no grupo da 'Região Sudeste'.
} 
127) partiu de testes realizados com informantes, "compreendendo estudantes universitários na área de Letras, jornalistas com formação universitária, professores universitários, diretoras e orientadoras de escolas primárias".

\section{Wherritt (1977)}

A partir de uma pesquisa de campo realizada em 1974, em São Paulo, Wherritt (1977) reúne gravações de conversação livre com informantes nascidos no estado de São Paulo (e muitos deles na capital). No estudo de Wherritt (1977), seus dados estão agrupados conforme o tipo de oração: substantiva, relativa, adverbial, independente e expressões estereotipadas, contemplando variação nos três tempos verbais do modo subjuntivo.

\section{Rocha (1997)}

Rocha (1997) investiga a variação no presente e no pretérito imperfeito do modo subjuntivo vs. modo indicativo em dados de orações substantivas introduzidas pela conjunção que. A amostra compreende dados de fala de informantes do Rio de Janeiro/RJ (Banco PEUL) e de Brasília. A seleção estatística dos grupos de fatores controlados obedece à seguinte ordem de significância: carga semântica do verbo ou do sintagma verbal da matriz, faixa etária, estrutura de assertividade da oração matriz, regularidade verbal e tipo de verbo da oração encaixada e tempo do verbo da oração matriz e tempo do verbo da oração encaixada.

\section{Alves Neta (2000)}

Para investigar a variação entre as formas verbais do presente do modo indicativo e do modo subjuntivo, Alves Neta (2000) examina dois córpus (falado e escrito) coletados na cidade de Januária, localizada no norte de Minas Gerais. Os contextos de análise são os seguintes: orações substantivas, adjetivas, adverbiais, coordenadas, principais e absolutas. Para os dados de fala, são consideradas estatisticamente significantes as variáveis 'tipo de oração' e 'nível de escolaridade'; para os dados de escrita, 'tipo de oração' e 'modalidade'.

\section{Gonçalves (2003)}

Para investigar a flutuação no uso dos três tempos do modo subjuntivo, Gonçalves (2003) coleta dados de produção oral de um projeto de formação de professores do ensino fundamental e médio e de especialistas, todos de um colégio público da cidade de Juiz de Fora/MG. Também fazem parte dos córpus dados coletados de programas de televisão e de situações cotidianas de comunicação. A autora investiga três contextos de análise: orações independentes, complementares e oblíquas.

\section{Guiraldelli (2004)}

Guiraldelli (2004) estuda o presente do modo subjuntivo e sua relação com a expressão das modalidades epistêmica, deôntica e volitiva, a partir da análise de um córpus escrito do português do Brasil: discursos políticos presidenciais e discursos de divulgação científica. No estudo do subjuntivo, a autora analisa as orações substantivas (âmbito sintático) e o valor semântico inerente ao verbo da oração principal (âmbito semântico). 


\section{Santos (2005)}

Santos (2005) investiga a variação entre o modo subjuntivo e o modo indicativo, nos três tempos verbais (presente, passado e futuro). $\mathrm{O}$ contexto de análise do subjuntivo compreende as orações complexas (substantivas e adverbiais), coletadas em dados de fala do Rio de Janeiro/RJ (Discurso \& Gramática) e dados de fala do noroeste de São Paulo/SP (Iboruna). Três variáveis apresentam relevância estatística: carga semântica do verbo da oração matriz (substantivas), grau de certeza epistêmica e tipo de oração subordinada, respectivamente.

\section{Almeida (2010)}

A pesquisa desenvolvida por Almeida (2010) contempla a análise de dados diacrônicos. Como objeto de estudo, a autora investiga o uso variável do presente e do imperfeito do modo subjuntivo em orações substantivas e em orações adverbiais concessivas em duas amostras: uma composta por textos escritos do século XIII ao século XX e outra composta por dados de fala culta (NURC-RJ/SSA) e não-culta (PEUL), em duas épocas distintas - de 1970 a 1990 e de 1980 a 2000. Para os dados de fala culta (NURC), são três as variáveis selecionadas: pessoa verbal, assertividade e tempo verbal. Para os dados de fala não-culta (PEUL), o subjuntivo é favorecido pelo tipo de verbo da oração matriz, pelo gênero e pelo tempo verbal da matriz. Para as orações concessivas nos dados de fala culta e não-culta, não há resultados probabilísticos.

\section{Barbosa (2011)}

Barbosa (2011) investiga, dentre outros fenômenos, a variação no uso do presente e a variação no uso do imperfeito do modo subjuntivo a partir de dados de informantes naturais da cidade de Vitória/ES. Para o cálculo probabilístico, o programa Goldvarb X seleciona as seguintes variáveis na ordem de significância: verbo da matriz, assertividade, tempo verbal da oração matriz e grau de escolaridade.

Uma análise geral das pesquisas realizadas na Região Sudeste aponta para resultados semelhantes encontrados na análise de dados da Região Sul: o tipo de oração e a modalidade (cf. ALVES NETA, 2000; GONÇALVES, 2003). Outras variáveis ainda revelam importância, como o grau de assertividade; o item verbal da oração matriz; carga semântica do verbo da oração matriz; o tipo de conjunção e a regularidade verbal. Com relação aos grupos de fatores sociais, as pesquisas, de uma forma geral, apontam para a importância do grau de escolaridade, ainda que diferentes resultados sejam encontrados.

\subsection{Região Nordeste}

\section{Meira (2006)}

Meira (2006) estuda o uso variável do modo subjuntivo nos três tempos com as respectivas formas do indicativo, em dois contextos: orações relativas e completivas. A amostra dos dados de fala pertence ao Acervo de Fala Vernácula do Português AfroBrasileiro, e quatro comunidades rurais de descendentes afro-brasileiros são investigadas, quais sejam: Barra e Bananal, Helvécia, Cinzento e Sapé. Sobre o controle das variáveis, quatro são selecionadas, respectivamente, sendo três de natureza linguística e uma de natureza social, quais sejam: localização temporal do evento 
expresso na oração relativa em relação ao momento da enunciação, tempo do subjuntivo previsto no uso culto, morfologia verbal e estada fora da comunidade ${ }^{26}$.

\section{Carvalho (2007)}

Carvalho (2007) desenvolve um estudo acerca da variação entre o modo subjuntivo e o modo indicativo em orações subordinadas substantivas introduzidas pela partícula que nos tempos presente e pretérito ${ }^{27}$. A amostra é constituída por dados de fala de informantes da região do Cariri, microrregião ao sul do estado do Ceará, extraídos do Banco de Dados dos Estudos de Língua Oral do Ceará. Para a variante presente do modo subjuntivo, o primeiro grupo de fatores selecionado pelo programa estatístico foi o tipo de verbo da oração principal, seguido pelos grupos de fatores estrutura da assertividade da oração e modalidade, já relevantes em outras pesquisas.

\section{Vieira (2007)}

A pesquisa conduzida por Vieira (2007), com amostras de dados de fala do Córpus Discurso \& Gramática (D\&G) da cidade de Natal/RN, tem o objetivo geral de investigar a variação entre modo subjuntivo e o modo indicativo, nos tempos presente e passado, a partir de dados de orações subordinadas substantivas.

\section{Oliveira (2007)}

A pesquisa realizada por Oliveira (2007) parte de dados de João Pessoa/PB, coletados do Projeto VALPB. A investigação do uso variável do presente e pretérito do modo subjuntivo concentra-se na análise de orações completivas introduzidas pelo complementizador que. Dentre as variáveis controladas, tipo semântico do verbo da oração matriz e grau de assertividade obtiveram relevância.

\section{Alves (2009)}

A pesquisa de Alves (2009) abrange dados de Muriaé/MG e de Feira de Santana/BA, que correspondem a estruturas alternativas para a expressão das modalidades típicas do subjuntivo em três tipos de sentenças: completivas, adverbiais e relativas. Por estruturas alternativas, Alves (2009, p. 31) entende "forma verbal no infinitivo, no gerúndio, nominalizada, elíptica, no futuro condicional e expressão com ter modal (ter que ou ter de + infinitivo)", formas essas consideradas variantes do presente do indicativo. A amostra da escrita está constituída por dados do texto História da Província Santa Cruz a que vulgarmente chamamos Brasil (século XVI). Em Muriaé, as seguintes variáveis foram selecionadas no contexto de orações completivas: escolaridade e $\operatorname{sexo}^{28}$. No contexto de orações relativas, foram as seguintes: sexo e faixa etária em Muriaé, e animacidade do antecedente do pronome relativo e nível de referência do antecedente em Feira de Santana.

As pesquisas realizadas com amostras da Região Nordeste reforçam a importância de variáveis também controladas em outros estudos resenhados nesta seção, a saber: assertividade da negação, modalidade, localização temporal do evento e classe semântica do verbo da oração principal.

Conforme mencionado, não encontramos pesquisas realizadas com dados da Região Norte. E com relação à Região Centro-Oeste, à exceção da pesquisa conduzida

\footnotetext{
${ }^{26}$ Devido ao número de dados, não foi possível submetê-los a rodadas estatísticas.

${ }^{27}$ Neste artigo, somente são apresentados resultados para a variação no presente do modo subjuntivo.

${ }^{28}$ Em Feira de Santana, o uso do subjuntivo é categórico.
} 
por Rocha (1997) com dados de Brasília (e também do Rio de Janeiro), temos conhecimento de uma dissertação de mestrado, desenvolvida por Tomanin (2003). Tendo como objetivo descrever a fala de Alto Araguaia ${ }^{29}$, a autora investiga diversos fenômenos linguísticos, dentre os quais destacamos o uso variável do presente do modo subjuntivo, também encontrado na fala de araguaienses. Registra a autora que o presente do subjuntivo é substituído pelo presente do indicativo preferencialmente por informantes menos escolarizados.

\subsection{Considerações acerca das pesquisas}

De uma forma geral, os pesquisadores submeteram os dados a um tratamento estatístico $^{30}$. A seguir, identificamos, através de um mapa do Brasil, as regiões de coleta dos dados de cada uma das pesquisas apresentadas. Para uma visualização mais abrangente da variação entre o modo subjuntivo e o modo indicativo, evidenciamos o percentual de uso do modo subjuntivo das pesquisas que fornecem tais resultados gerais, e, dependendo do estudo, destacamos o percentual de variação entre o presente do subjuntivo e o presente do indicativo. Ressaltamos, entretanto, que a importância dos percentuais reside na indicação da frequência do subjuntivo em cada amostra investigada. Qualquer comparação mais rigorosa inferida a partir dos resultados deve considerar as particularidades de cada estudo, dentre as quais destacamos o contexto de objeto de análise, os tempos verbais eleitos para análise, o número de dados da amostra e a constituição do banco.

\footnotetext{
${ }^{29}$ Alto Araguaia é um município do estado do Mato Grosso, localizado na divisa com Goiás.

${ }^{30}$ Das pesquisas consideradas, seis não apresentam um controle probabilístico aplicado às variáveis: Botelho Pereira (1974), Wherritt (1977), Costa (1990), Gonçalves (2003), Guiraldelli (2004) e Vieira (2007).
} 
Figura 1 Panorama do uso variável do modo subjuntivo (diferentes tempos verbais) em diferentes cidades do Brasil

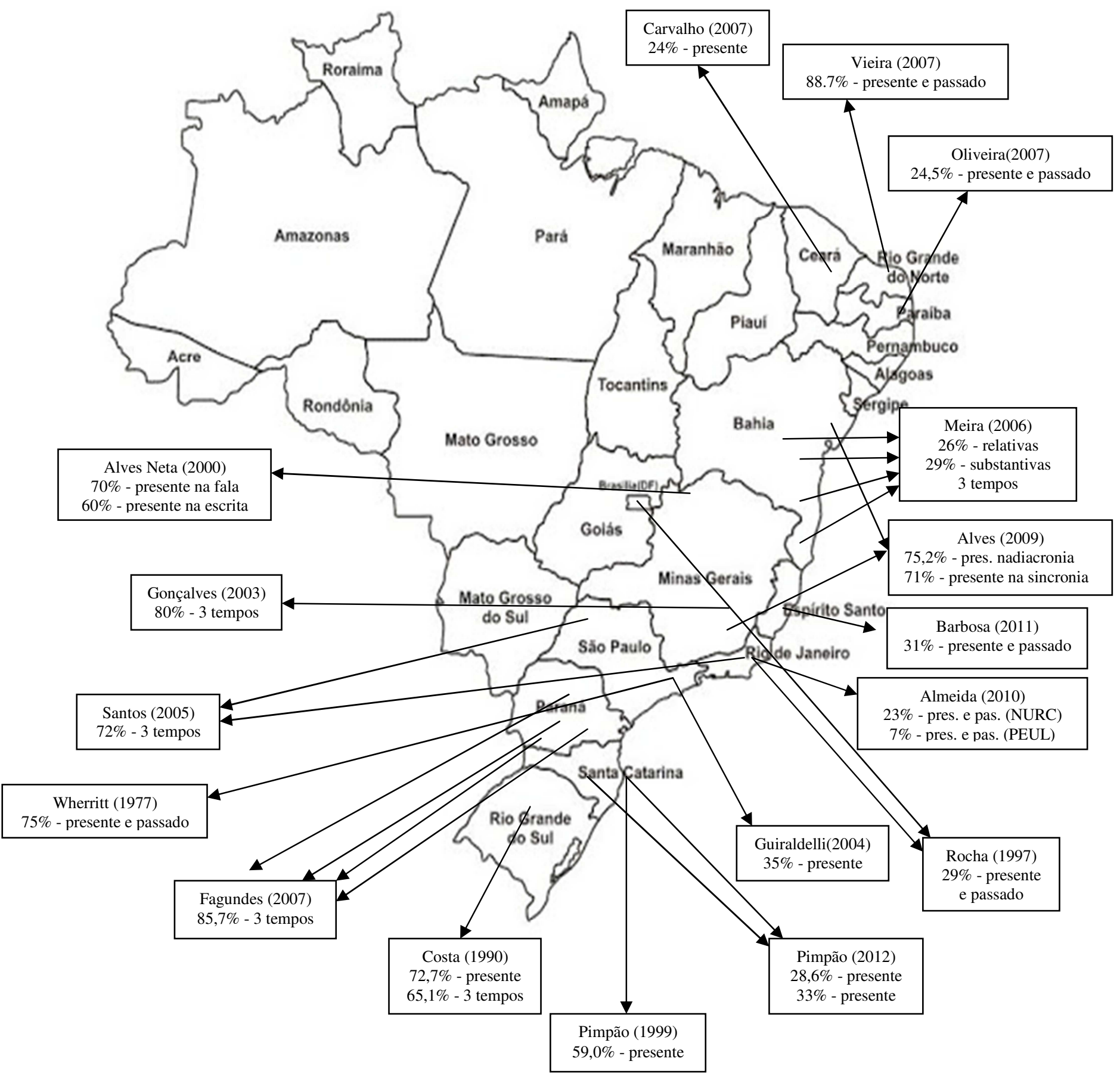

Julgamos pertinente destacar, em um primeiro momento, o cuidado na comparação de resultados percentuais gerais para o uso variável do modo subjuntivo (cf. mapa). Esses resultados são importantes na medida em que indicam a frequência de subjuntivo em cada amostra investigada, entretanto o pesquisador não deve descuidar de fatores importantes, tais como o contexto de subjuntivo controlado e os tempos verbais analisados, por exemplo. Essa atenção à caracterização do objeto de estudo e à 
composição da amostra não inviabiliza uma análise comparativa entre pesquisas, necessária para um maior conhecimento de diversos fenômenos linguísticos. No entanto, análises dessa natureza devem ser relativizadas em função de diferentes variáveis, pois, se essas diferenças não forem levadas em consideração, o analista pode vir a comparar objetos não plenamente comparáveis (PIMPÃO; GÖRSKI, 2010).

Apenas para citar um exemplo. Se observarmos o mapa e retomarmos alguns resultados para o uso variável do presente do subjuntivo, identificamos um alto percentual dessa variante em Costa (1990) - 72,7\% - e Alves Neta (2000) - 70\% - e um percentual mais baixo em Guiraldelli (2004) - 35\% - e Carvalho (2007) - 24\%. Uma análise restrita a essas frequências gerais poderia indicar comportamentos distintos do presente do subjuntivo por região. Entretanto, um olhar mais atento aos dados das pesquisas de Guiraldelli (2004) e Carvalho (2007) aponta para o seguinte: no trabalho de Guiraldelli (2004), há um uso muito maior de verbos epistêmicos, que tendem a favorecer o indicativo, do que de verbos deônticos e volitivos, que tendem a favorecer o subjuntivo. Carvalho (2007) controla verbos da matriz, como dizer, saber, contar, que tendem a co-ocorrer com o indicativo na subordinada, além do verbo achar, praticamente de uso categórico do presente do indicativo e muito recorrente na amostra. Nesse sentido, resultados percentuais gerais constituem apenas o ponto de partida para uma análise comparativa.

Poderíamos, ainda, confrontar os percentuais mencionados no parágrafo anterior com o percentual de presente do modo subjuntivo encontrado por Pimpão (1999) 59\%. Esse resultado situa-se entre o de Costa (1990) - 72,7\% - e Alves Neta (2000) $70 \%$-, de um lado, e o de Guiraldelli (2004) - 35\% -,de Carvalho (2007) - 24\% -, de Pimpão (2012) - 28,6\% para Florianópolis e 33\% para Lages - de outro. Talvez essa diferença possa ser atribuída a três fatores: em primeiro, na pesquisa de Costa (1990), há poucos dados para os seguintes contextos de análise: oração relativa, oração adverbial e modalizadores talvez e tomara, totalizando 23 usos de subjuntivo em 34 ocorrências. Em segundo, Alves Neta (2000) não considerou determinados dados de oração relativa por acreditar que o uso do modo verbal sinaliza, por si só, a modalidade, não havendo, portanto, variação, motivo pelo qual excluiu esses dados da análise. O terceiro fator diz respeito aos casos com o verbo achar, verbo que compreende aproximadamente $50 \%$ da amostra de Pimpão (2012). É provável que tais motivos estejam contribuindo para a diferença nos percentuais.

$\mathrm{Na}$ tentativa de buscar explicações para os resultados de subjuntivo com percentual inferior a 50\%, recorremos novamente às pesquisas e apresentamos duas possíveis justificativas para a diferença de percentuais: (i) um uso mais recorrente de verbos epistêmicos, que tendem a ocorrer com o indicativo; e (ii) o controle do verbo achar, que apresenta um número expressivo de ocorrências e, muito frequentemente, está acompanhado do indicativo. Com relação ao primeiro ponto, e conforme já mencionado, na pesquisa realizada por Guiraldelli (2004), há um número maior de verbos epistêmicos, o que pode estar elevando o uso do indicativo. $\mathrm{O}$ mesmo ocorre na pesquisa de Almeida (2010), que encontra 23\% de uso do subjuntivo nos dados do NURC e $7 \%$ nos dados do PEUL, sendo que os dados correspondem a casos de verbos epistêmicos.

No que diz respeito ao controle do verbo achar, mencionamos as pesquisas conduzidas por Rocha (1997), Carvalho (2007), Oliveira (2007), Barbosa (2011) e Pimpão (2012). Nesses estudos, o percentual de uso do subjuntivo é baixo: $29 \%, 24 \%$, $21,6 \%, 31 \%$ e $28,6 \% / 33 \%{ }^{31}$, respectivamente (cf. mapa). Entretanto, as pesquisadoras

\footnotetext{
${ }^{31}$ O percentual de 28,6\% corresponde aos dados de Florianópolis; o percentual de 33\%, aos de Lages
} (PIMPÃO, 2012). 
controlam dados com o verbo achar que, além de muito frequente nos córpus consultados, tende a ocorrer com o indicativo, considerando o baixo percentual para o modo subjuntivo com esse verbo: $4 \%, 12 \%, 2 \%$ e $5 \%$, respectivamente. Controlado junto com outros verbos, o verbo achar pode contribuir para uma aparente preferência pelo indicativo. Não temos, apenas, justificativa para os resultados de $23 \%$ (oração relativa) e de $29 \%$ (oração substantiva) para o uso do subjuntivo na pesquisa de Meira (2006).

A seguir, reproduzimos o mapa anterior, com novos percentuais para o uso do subjuntivo nas pesquisas de Rocha (1997), Carvalho (2007), Oliveira (2007) e Barbosa (2011). Para alcançar esses resultados, excluímos os dados com o verbo achar. Considerando que na pesquisa desenvolvida por Oliveira (2007) há um grupo de verbos de alta frequência, decidimos também excluí-lo sob pena de distorcer os resultados ${ }^{32}$.

\footnotetext{
${ }^{32} \mathrm{Na}$ pesquisa de Oliveira (2007), o grupo de verbos intitulado verbo indiferente performativo (falar, dizer) e condicional (ser certo) tem um total de 206 ocorrências, dentre as quais apenas 2 ocorrem com o subjuntivo.
} 
Figura 2 Panorama do uso variável do modo subjuntivo (diferentes tempos verbais) em diferentes cidades do Brasil - dados com o verbo achar excluídos

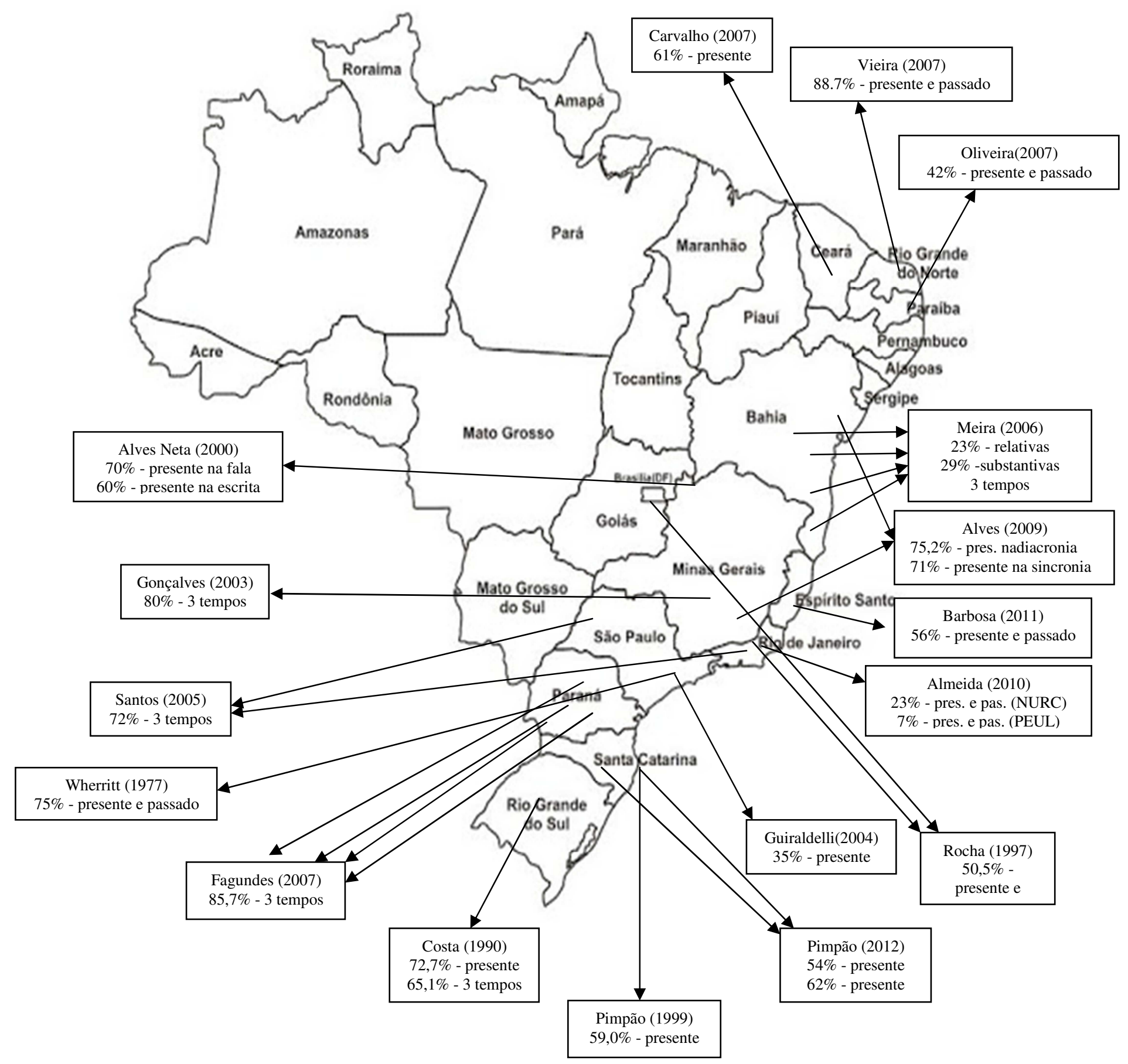

De acordo com esse segundo mapa, observamos alteração nos resultados nas cinco pesquisas destacadas se desconsiderados os dados com o verbo achar: o uso de subjuntivo na pesquisa de Rocha (1997) passa de $29 \%$ para 50,5\%; na pesquisa de Carvalho (2007), de $24 \%$ para $61 \%$; na de Oliveira (2007), de $24,5 \%$ para $42 \%$; no 
estudo de Barbosa (2011), o resultado inicial de $31 \%$ sobe para $56 \%$; e, no de Pimpão (2012), de 28,6\% para 54\% na amostra de Florianópolis e de 33\% para 62\% na amostra de Lages. Dessa forma, uma análise em termos frequenciais gerais não pode descuidar, por exemplo, do item verbal envolvido na quantificação.

A seguir, tecemos considerações acerca de duas variáveis controladas nas diferentes pesquisas, e dos respectivos resultados, por terem se mostrado as mais recorrentes: modalidade e tipo de oração. Começamos com a variável modalidade. $\mathrm{O}$ critério metodológico aplicado a essa variável não se mostra homogêneo entre os trabalhos resenhados, o que dificulta uma comparação mais estreita entre os resultados das pesquisas. Isso se deve, em parte, à filiação teórica do investigador, a qual é responsável por contribuir com elementos para a constituição dos fatores que compõem as variáveis linguísticas. É nesse sentido que trabalhos seguem um enfoque mais semântico ou mais discursivo-pragmático, mais formal ou mais funcional, a depender do lugar teórico do pesquisador. Ademais, acreditamos que a complexidade que envolve a própria noção de modalidade - conforme se mostrou evidente nos estudos acerca do modo subjuntivo realizados com dados do português do Brasil - é um complicador para uma análise comparativa de resultados.

Em Fagundes (2007), o controle da modalidade é binário: conhecimento (epistêmico) e conduta/desejo (deôntico); Guiraldelli (2004) já segue uma orientação tripartida da modalidade: epistêmico, deôntico e volitivo. A modalidade em Alves Neta (2000) diz respeito a quatro valores: volição, desejo, causa/necessidade e existência possível. Ainda assim, como convergência de resultados, podemos destacar a associação entre verbos deônticos e/ou volitivos e o uso do subjuntivo, independentemente de tempo verbal e de número de ocorrências (cf. ALVES NETA, 2000; GONÇALVES, 2003; GUIRALDELLI, 2004; MEIRA, 2006; FAGUNDES, 2007; CARVALHO, 2007; VIEIRA, 2007). A maioria desses trabalhos, no entanto, controla a modalidade nas orações substantivas. Em Pimpão (1999; 2012), seguindo a previsão funcionalista de que as categorias não são discretas, a proposta é distribuir o uso variável do presente do subjuntivo em um continuum, abrangendo todos os contextos sintáticos, conforme discutido adiante.

À semelhança da variável modalidade, o tipo de oração é controlado em diversas pesquisas, em algumas, inclusive, a variável recebe o mesmo nome, ainda que os fatores não sejam plenamente idênticos, nem, muitas vezes, os tempos do subjuntivo analisados. O quadro a seguir mostra o nome dessa variável nos trabalhos, bem como apresenta o fator com percentual mais elevado para o uso do modo subjuntivo. 
Quadro 1: Atuação de um mesmo tipo de variável estrutural sobre o uso do modo subjuntivo (diferentes estudos)

\begin{tabular}{|c|c|c|}
\hline VARIÁVEL INDEPENDENTE & FATOR & $\%$ \\
\hline Fatores estruturais (COSTA, 1990) $\mathrm{PS}^{33}$ & sub.introd. por conj. integrante & 76,7 \\
\hline Tipo de contexto subjuntivo (PIMPÃO, 1999) PS & oração com advérbio talvez & 67 \\
\hline Tipo de contexto sintático (PIMPÃO, 2012) PS & oração substantiva (FLP) & 62 \\
\hline Tipo de contexto sintático (PIMPÃO, 2012) PS & oração parentética (LGS) & 87 \\
\hline Tipo de oração (ALVES NETA, 2000) PS fala & subordinada substantiva & 82 \\
\hline Tipo de oração (ALVES NETA, 2000) PS escrita & subordinada adjetiva & 64 \\
\hline Tipo de oração (WHERRITT, 1977) S & subordinada adjetiva & 90 \\
\hline Tipo de oração (FAGUNDES, 2007) S & subordinada substantiva & 94 \\
\hline Tipo de oração subordinada (SANTOS, 2005) S & subordinada completiva $^{34}$ & 71 \\
\hline Tipo de oração substantiva (VIEIRA, 2007) S & subordinada objetiva direta & 72,3 \\
\hline
\end{tabular}

Conforme o Quadro 1, quatro trabalhos apresentam o mesmo nome para a variável tipo de oração. Alves Neta (2000) investiga a variação no presente do subjuntivo nas seguintes orações: substantiva, relativa, adverbial, coordenada, principal e absoluta. Fagundes (2007) controla as substantivas, adjetivas, adverbiais, isoladas e principais nos três tempos verbais do modo subjuntivo. Em Wherritt (1977), as orações são: substantiva, relativa, adverbial, independente e expressões estereotipadas, nos três tempos verbais do subjuntivo. Em Santos (2005), os três tempos do subjuntivo são analisados em contextos de orações subordinadas encaixadas e adverbiais. Em Vieira (2007), a pesquisa fica concentrada na oração substantiva objetiva direta. Em outras pesquisas, o nome da variável difere, mas os fatores são praticamente os mesmos: Costa (1990), Pimpão (1999) e Pimpão (2012) controlam orações substantivas, adjetivas, adverbiais e com o advérbio talvez. A diferença está em Costa (1990), com as orações exortativas, e em Pimpão (1999), com contextos de pressuposição, renomeados para oração parentética em Pimpão (2012). Observa-se, portanto, convergências e divergências em termos de variável independente e dos fatores que a compõem. Em vista disso, os resultados também não autorizam uma comparação mais estreita; parecenos, portanto, que uma análise mais micro - em termos de item verbal da matriz, classe semântica do verbo matriz e tipo de conjunção - pode propiciar uma investigação mais acurada e mais segura.

As clássicas variáveis de natureza social apresentam relevância estatística em algumas pesquisas. A variável sexo/gênero não exibe uniformidade em termos de resultados: na pesquisa de Pimpão $(1999 ; 2012)$ com amostras de Florianópolis/SC, os informantes masculinos preferem o uso do subjuntivo, resultado próximo ao encontrado por Alves (2009) em Muriaé/MG. Em Almeida (2010), dados do PEUL/RJ indicam a tendência das mulheres ao uso do subjuntivo. Para a variável idade, o estudo de Carvalho (2007), com dados do Cariri/CE, indica que falantes acima de 50 anos tendem a preservar o uso do subjuntivo; e o estudo de Alves (2009) também mostra a importância dos informantes mais velhos de Muriaé (52 a 60 anos) no condicionamento desse mesmo modo verbal. Entretanto, outras pesquisas apresentam resultados diferentes.

\footnotetext{
${ }^{33}$ PS indica que somente o presente do subjuntivo foi investigado e $\mathrm{S}$, em outros estudos, indica que mais de um tempo do modo subjuntivo foi controlado como objeto de análise.

${ }^{34}$ No trabalho de Santos (2005), as orações concessiva, final e comparativa apresentam uso categórico de modo subjuntivo, porém há, nos córpus investigados, somente 10 dados. O primeiro tipo de oração que apresenta variação com preferência pelo modo subjuntivo em termos percentuais é a oração condicional, porém, como, em geral, não ocorre no tempo presente, preferimos não mencionar na tabela.
} 
Para a variável escolaridade, a pesquisa de Pimpão (1999) revela que informantes florianopolitanos de nível primário e colegial usam mais subjuntivo se comparados aos falantes do ginasial. Em Pimpão (2012), os resultados indicam que informantes com colegial usam mais o presente do subjuntivo, tanto em Florianópolis quanto em Lages. O estudo de Alves Neta (2000) indica que o emprego do subjuntivo acompanha o nível de escolaridade dos informantes de Januária/MG. Na pesquisa de Carvalho (2007), os informantes cearenses sem escolaridade empregam o modo subjuntivo. Ao contrário desse resultado, dados controlados por Alves indicam o ensino superior como fator significativo para o uso do subjuntivo pelos mineiros de Muriaé (2009) (cf. PIMPÃO, 2011).

Observamos pouca tendência na mesma direção em termos de resultados para as variáveis sociais. Talvez cruzamentos entre variáveis sociais e linguísticas possam identificar os grupos de fatores que, de fato, mostram-se relevantes no condicionamento do subjuntivo. A composição do córpus e o número de dados também podem contribuir para resultados um tanto diferenciados.

Outras variáveis de natureza extralinguística merecem referência: a periodização histórica, controlada por Almeida (2010), na tentativa de indicar contextos de emergência do presente do indicativo, e o informante, com o objetivo de observar a questão da variação na comunidade e a variação no indivíduo. Dentre as variáveis extralinguísticas, destacamos a cidade. Considerada por alguns pesquisadores (FAGUNDES, 2007; OLIVEIRA, 2007; ALVES, 2009; PIMPÃO, 2012), a cidade tem esclarecido resultados para as localidades investigadas.

$\mathrm{Na}$ consideração de todos esses fatores, acreditamos que alguma diferença no uso variável do presente do modo subjuntivo deva contribuir não só para a identificação do perfil do informante de cada uma das cidades, como também para a caracterização de comunidades distintas (GUY, 2000, 2001). A pesquisa de Fagundes (2007) mostrou que diferentes cidades podem selecionar diferentes variáveis - Curitiba e Irati selecionam o grupo de fatores modalidade; a cidade de Pato Branco, o grupo tipo de oração; e a cidade de Londrina não seleciona nenhum grupo. Meira (2006) controla a localidade do informante na pesquisa que realiza a partir de dados de fala de comunidades afrodescendentes do estado da Bahia. Nesse estudo, conclui a autora haver baixo índice de modo subjuntivo nas orações substantivas nas quatro comunidades investigadas. Para as orações adjetivas, encontra um percentual que varia entre $18 \%$ e $31 \%$ dentre as mesmas comunidades, evidenciando, também, um baixo uso do modo subjuntivo. Também o estudo de Alves (2009) indicou um comportamento diferenciado entre os informantes das duas cidades investigadas: Muriaé e Feira de Santana, permitindo à autora constatar que há uma tendência a usar menos subjuntivo em Muriaé como decorrência do "fenômeno evite o subjuntivo", que estaria mais avançado em Minas Gerais (ALVES, 2009, p. 40). Pimpão (2012) observa um uso diferenciado de presente do modo subjuntivo: em Florianópolis, o resultado atinge um percentual de 54\%; em Lages, conforme esperado, o percentual é mais elevado: $62 \%$.

\section{CONSIDERAÇÕES FINAIS}

O mapeamento dos 18 estudos desenvolvidos com dados do português do Brasil, contemplando quatro das cinco regiões do Brasil - Sul, Sudeste, Nordeste e CentroOeste - não está concluído. Existem outras pesquisas que devem ser consideradas, e cujos resultados devem constar nos mapas apresentados. Ainda assim, o mapeamento inicial permite um panorama muito interessante sobre o uso variável do modo subjuntivo e coloca em destaque algumas variáveis, como modalidade e tipo de oração. A despeito de especificidades que caracterizam as amostras e o controle das variáveis, o 
uso variável do modo subjuntivo parece seguir um certo padrão, pelo menos no que se refere às duas variáveis mencionadas. Os trabalhos constituem referência, portanto, para a comparação deresultados relativos às mesmas variáveis na tentativa de uma maiorcompreensão do funcionamento do uso variável do presente do subjuntivo.

\section{REFERENCIAS}

ALMEIDA, E. S. de. Variação de uso do subjuntivo em estruturas subordinadas: do século XIII ao XX. 2010. 294f. Tese (Doutorado em Letras Vernáculas) - Faculdade de Letras, Universidade Federal do Rio de Janeiro, Rio de Janeiro, 2010.

ALVES NETA, A. $O$ uso de formas do indicativo por formas do subjuntivo no português brasileiro. 2000. 114f. Dissertação (Mestrado em Letras: Linguística) Faculdade de Letras, Universidade Federal de Minas Gerais, Belo Horizonte, 2000.

ALVES, R. F. A expressão de modalidades típicas do subjuntivo em duas sincronias do português: século XVI e contemporaneidade. 2009. 197f. Tese (Doutorado em Linguística) - Instituto de Estudos da Linguagem, Universidade Estadual de Campinas, Campinas, 2009.

AZEREDO, J. C. de. Gramática Houaiss da língua portuguesa. 2. ed. São Paulo: Publifolha, 2008.

BARBOSA, A. F. Alternância de formas indicativas e subjuntivas na fala de Vitória (ES). 2011. 146f. Dissertação (Mestrado em Linguística) - Universidade Federal do Espírito Santo, Vitória, 2011.

BECHARA, E. Moderna gramática portuguesa. 37. ed. (revista e ampliada). Rio de Janeiro: Lucerna, 2006.

BOTELHO PEREIRA, M. A. Aspectos da oposição modal indicativo/subjuntivo no português contemporâneo. 1974. 265f. Dissertação (Mestrado em Língua Portuguesa) Universidade Federal do Rio de Janeiro, Rio de Janeiro, 1974.

CARVALHO, H. M. de. A alternância indicativo/subjuntivo nas orações substantivas em função dos tempos verbais presente e imperfeito na língua falada do Cariri. 2007. 158f. Tese (Doutorado em Linguística) - Departamento de Letras Vernáculas, Universidade Federal do Ceará, Fortaleza, 2007.

CEGALlA, D. P. Novíssima gramática da língua portuguesa. 46. ed. São Paulo: Companhia Editora Nacional, 2007.

COSTA, I. B. O verbo na fala de camponeses: um estudo de variação. 1990. 223f. Tese (Doutorado em Linguística) - Instituto de Estudos da Linguagem, Universidade Estadual de Campinas, Campinas, 1990.

CUNHA, C. Gramática da língua portuguesa. Rio de Janeiro: FAE, 1992.

CUNHA, C.; CINTRA, L. Nova gramática do português contemporâneo. 4. ed. Rio de Janeiro: Lexikon Editora Digital, 2007.

FAGUNDES, E. D. As ocorrências do modo subjuntivo nas entrevistas do VARSUL no estado do Paraná e as possibilidades de variação com o modo indicativo. 2007. 220f. Tese (Doutorado em Letras) - Ciências Humanas, Letras e Artes, Universidade Federal do Paraná, Curitiba, 2007.

GONÇALVES, J. R. Considerações sobre a flutuação no emprego do subjuntivo em contextos orais do Português do Brasil. 2003. 100f. Dissertação (Mestrado em Letras) Departamento de Letras, Pontifícia Universidade Católica, Rio de Janeiro, 2003.

GUIRALDELLI, L. A. O modo subjuntivo e a expressão das modalidades epistêmica, deôntica e volitiva. 2004. 104f. Dissertação (Mestrado em Estudos Linguísticos) Instituto de Biociências, Letras e Ciências Exatas,Universidade Estadual Paulista, São José do Rio Preto, 2004. 
GUY, G. A identidade linguística da comunidade de fala: paralelismo interdialetal nos padrões de variação linguística. Organon, Porto Alegre, v. 14, n. 28 e 29, p. 17-32. 2000 .

As comunidades de fala: fronteiras internas e externas. In: II Congresso Internacional da Abralin, Fortaleza: Universidade Federal do Ceará, 2001.

MEIRA, V. O uso do modo subjuntivo em orações relativas e completivas no português afro-brasileiro. 2006. 317f. Dissertação (Mestrado em Letras e Linguística) - Instituto de Letras, Universidade Federal da Bahia, Salvador, 2006.

MENDES DE ALMEIDA, N. Gramática metódica da língua portuguesa. 45. ed. São Paulo: Saraiva, 2005.

OLIVEIRA, M. do C. de. O uso do modo verbal em estruturas de complementação no português do Brasil. 2007. 155f. Dissertação (Mestrado em Linguística) - Instituto de Letras, Universidade de Brasília, Brasília, 2007.

PIMPÃO, T. S. A 'escolaridade' e o emprego variável do modo subjuntivo no Português Brasileiro. In: Anais da ALFAL, Alcalá de Henares, 2011.

Uso variável do presente do modo subjuntivo: uma análise de amostras de fala e escrita das cidades de Florianópolis e Lages nos séculos XIX e XX. 2012. 350f. Tese (Doutorado em Linguística) - Centro de Comunicação e Expressão, Universidade Federal de Santa Catarina, Florianópolis, 2012.

Variação no presente do modo subjuntivo: uma abordagem discursivopragmática. 1999. 129f. Dissertação (Mestrado em Linguística) - Centro de Comunicação e Expressão, Universidade Federal de Santa Catarina, Florianópolis, 1999.

PIMPÃO, T. S.; GÖRSKI, E. M. Interpretação qualitativa de resultados quantitativos: uma análise do processo metodológico na comparação de diferentes pesquisas. Working Papers em Linguística, Florianópolis, n. 1, p. 71-81. 2010.

ROCHA, R. C. A alternância indicativo/subjuntivo nas orações subordinadas substantivas em português. 1997. 125f. Dissertação (Mestrado em Linguística) Departamento de Linguística, Línguas Clássicas e Vernáculas, Universidade de Brasília, Brasília, 1997.

SAID ALI, M. Gramática histórica da língua portuguêsa. 7. ed. São Paulo: Melhoramentos, 1971.

SANTOS, R. M. A. dos. O uso variável do modo subjuntivo em estruturas complexas. 2005. 170f. Dissertação (Mestrado em Estudos Linguísticos) - Instituto de Biociências, Letras e Ciências Exatas, Universidade Estadual Paulista, São José do Rio Preto, 2005.

TOMANIN, C. R. Fotografias da fala de Alto Araguaia - MT. 2003. 197f. Dissertação (Mestrado em Linguística) - Instituto de Estudos da Línguagem, Universidade Estadual de Campinas, Campinas, 2003.

VIEIRA, M. M. M. Alternância no uso dos modos indicativo e subjuntivo em orações subordinadas substantivas: uma comparação entre o português do Brasil e o francês do Canadá. 2007. 106f. Dissertação (Mestrado em Letras) - Departamento de Letras, Universidade Federal do Rio Grande do Norte, Natal, 2007.

WHERRITT, I. M. The subjunctive in Brazilian Portuguese. 1977. 191f. Tese (DoutoradoemFilosofia) - Department of Modern and Classical Languages, University of New Mexico, Albuquerque, 1977.

Data de submissão: 23/05/2014

Data de aceite: 20/08/2014 